\title{
Characteristics of the naturalized flora of Southern Africa largely reflect the non-random introduction of alien species for cultivation
}

\author{
Ali Omer, Trevor Fristoe, Qiang Yang, Noëlie Maurel, Patrick Weigelt, Holger Kreft, Jonas Bleilevens, \\ Wayne Dawson, Franz Essl, Jan Pergl, Petr Pyšek and Mark van Kleunen
}

A. Omer (https://orcid.org/0000-0001-5687-3386) \ (ali.omer@uni-konstanz.de), T. Fristoe, Q. Yang, N. Maurel (https://orcid.org/0000-0002-70391794), J. Bleilevens and M. van Kleunen, Ecology, Dept of Biology, Univ. of Konstanz, Konstanz, Germany. AO also at: Dept of Forest Management, Faculty of Forestry, Univ. of Khartoum, North Khartoum, Sudan. - P. Weigelt and H. Kreft (https://orcid.org/0000-0003-4471-8236), Biodiversity, Macroecology and Biogeography, Univ. of Goettingen, Göttingen, Germany. HK also at: Centre of Biodiversity and Sustainable Land Use (CBL), Univ. of Goettingen, Göttingen, Germany. - W. Dawson, Dept of Biosciences, Durham Univ., Durham, UK. - F. Essl (https://orcid.org/0000-0001-8253-2112), Division of Conservation Biology, Vegetation- and Landscape Ecology, Dept of Botany and Biodiversity Research, Univ. of Vienna, Vienna, Austria. - J. Pergl and P. Pyšek, Czech Academy of Sciences, Inst. of Botany, Dept of Invasion Ecology, Prühonice, Czech Republic. PP also at: Dept of Ecology, Faculty of Science, Charles Univ., Prague, Czech Republic. MVK also at: Zhejiang Provincial Key Laboratory of Plant Evolutionary Ecology and Conservation, Taizhou Univ., Taizhou, China.

Konstanzer Online-Publikations-System (KOPS) URL: http://nbn-resolving.de/urn:nbn:de:bsz:352-2-1n9rgj48kcol41

\section{Ecography}

44: $1812-1825,2021$ doi: $10.1111 /$ ecog.05669

Subject Editor: Jason Pither Editor-in-Chief: Miguel Araújo Accepted 2 September 2021

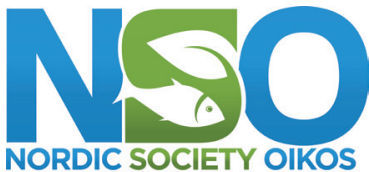

www.ecography.org
Biological invasions are one of the most defining features of the Anthropocene. Most studies on biological invasions focus on the later stages of the invasion process, that is after species have already become naturalized. It is frequently overlooked, however, that patterns in origin, phylogeny and traits of naturalized alien species might largely reflect which species have been introduced in the first place. Here, we quantify and assess such introduction biases by analyzing 5317 plant species introduced for cultivation (i.e. primarily as ornamental garden plants) in the 10 countries composing Southern Africa. We show that this cultivated alien flora represents a non-random subset of the global flora and that this bias at the introduction stage largely contributes to patterns in geographic origin, phylogenetic composition and traits of the naturalized flora. For example, while species from Australasia are, compared to the global flora, disproportionally overrepresented in the naturalized cultivated flora of Southern Africa, this pattern is driven by their higher likelihood of introduction for cultivation. The same is true for the overrepresentation of free-standing woody species in the naturalized cultivated flora. The strong phylogenetic clustering of the naturalized cultivated flora is also, to a large extent, driven by introduction bias. Although functional traits explained little variation in naturalization success of cultivated plants, naturalization success was more likely for plants with intermediate seed mass and height and high specific leaf area. Thus, despite strong biases in which species have been introduced to Southern Africa, there are significant patterns in the species characteristics related to naturalization probability. Our quantification of introduction biases demonstrates that they are huge, and that accounting for it is important to avoid over- or underemphasizing the characteristics of successfully naturalized alien plants.

Keywords: as invasive plants, biological traits, geographical origin, horticulture, naturalization extent, naturalization success, non-native plants

(C) 2021 The Authors. Ecography published by John Wiley \& Sons Ltd on behalf of Nordic Society Oikos This is an open access article under the terms of the Creative Commons Attribution License, which permits use, distribution and reproduction in any medium, provided the original work is properly cited. 


\section{Introduction}

Anthropogenic activities are increasingly changing abiotic and biotic components of the biosphere (Lewis and Maslin 2015). The exchange of biota among different parts of the globe is one of the most pervasive of these human-made changes. As a result, over 13000 vascular plant species have now invaded regions outside their known native geographic ranges (van Kleunen et al. 2015a). While the invasion process consists of four stages - transport, introduction, establishment (i.e. naturalization) and spread (i.e. advancing to become invasive) (Richardson et al. 2000, Blackburn et al. 2011) - most research focuses on the last two stages (but see Hulme et al. 2008, Faulkner et al. 2020). As a consequence, still little is known about what characterizes the introduced species in a region, irrespective of whether they have naturalized or not.

As naturalized species (and ultimately invasive species) emerge from the pool of introduced species, it is important to know whether species with specific characteristics are more likely to have been introduced than expected by chance (i.e. whether there is a so-called introduction bias; Chrobock et al. 2011, Maurel et al. 2016). Species originating in certain regions (e.g. Europe) and certain plant lineages (e.g. species in the Pinaceae family) have been more successful at becoming naturalized than others (Pyšek et al. 2017). Naturalization success is also positively correlated with native range size (Cadotte et al. 2006). However, with a few exceptions (Bradley et al. 2012, McGregor et al. 2012, Moodley et al. 2013, Gippet and Bertelsmeier 2021, Palma et al. 2021), it is not known whether species from certain continents and families and with certain native range sizes are over-represented among naturalized species because they were more likely to be transported and introduced elsewhere (i.e. they show an introduction bias), or because they have a higher inherent ability to naturalize once introduced. Accounting for biases resulting from the characteristics of species that have been introduced is therefore an essential, but rarely considered, step for understanding geographic, ecological and phylogenetic patterns in naturalization success (Palma et al. 2021).

Investigations into plant characteristics associated with invasion success started with Herbert Baker's publication of a list of characteristics of the 'ideal weed' (Baker 1965). Since then many studies have searched for biological traits (e.g. growth form, height, seed mass, specific leaf area) or geographic, phylogenetic and ecological characteristics that promote invasion success (Hamilton et al. 2005, Pyšek and Richardson 2007, Bucharova and van Kleunen 2009, Pyšek et al. 2009, Ordonez et al. 2010, Kueffer et al. 2013, van Kleunen et al. 2015b, Haeuser et al. 2018). While some traits appear to be frequently associated with naturalized or invasive species, literature reviews have also revealed a lack of predictive power and inconsistent associations between plant traits and invasion success (Pyšek and Richardson 2007, van Kleunen et al. 2015b, Ansong et al. 2018). This could be because the effects of traits on invasion success are context-dependent, vary among regions and environments (Kueffer et al. 2013), among invasion stages (Dawson et al. 2009, Moodley et al. 2013) and with respect to the dimension of invasiveness considered (e.g. abundance or impact, Fristoe et al. 2021, Liao et al. 2021). Furthermore, most studies considered only linear relationships between invasion success and traits (but see Küster et al. 2008, Haeuser et al. 2018), although many relationships may be non-linear (van Kleunen et al. 2015b). So, to improve our understanding of the role of plant characteristics in naturalization success, we need to quantify and account for biases associated with the introduction stage (Maurel et al. 2016) and to test for non-linear effects (Ansong et al. 2018).

Many alien organisms have been unintentionally introduced (Hulme et al. 2008), and comprehensive data for such introductions are lacking. Hence it is not possible to know all species that have ever been introduced to a region. However, in the case of vascular plants, the majority of alien species have been intentionally introduced for cultivation (Reichard and White 2001, Lambdon et al. 2008, Dodd et al. 2015, Faulkner et al. 2016). At least $75 \%$ of the -13000 naturalized alien plants worldwide are known to be grown in domestic gardens somewhere around the globe (van Kleunen et al. 2018), and plants with economic use are 18 times more likely to naturalize than those without economic use (van Kleunen et al. 2020). So, introduced cultivated floras offer valuable, yet underutilized, data sources for quantifying biases in the types of plants humans have selected from the global flora for introduction into cultivation, and the consequences of such introduction biases for patterns in the origins, phylogenetic composition and traits of the plants that naturalized (Maurel et al. 2016, Pergl et al. 2016). Without such information, we might draw incorrect conclusions about what drives naturalization success.

Here, we used a checklist of the cultivated flora (i.e. primarily ornamental garden plants) of Southern Africa (Glen 2002), to test whether these species represent a more biased subset of the global flora outside of Southern Africa than expected by chance. This was done in terms of the geographic origins, phylogenetic composition and traits of the cultivated alien species. In addition, we tested whether those that have become naturalized deviate from the ones that were brought into cultivation and have not escaped and naturalized. Specifically, we aimed to: 1) quantify the degree to which biases in the composition of the introduced cultivated flora explain patterns of the naturalized flora in Southern Africa with regard to the continent of origin, native range size, phylogeny and growth form, and 2) quantify how plant functional traits (i.e. seed mass, height and specific leaf area) mediate the naturalization success of cultivated plants in Southern Africa.

\section{Methods}

\section{The cultivated and naturalized floras of Southern Africa}

A list of taxa (including species, subspecies and varieties; for simplicity hereafter jointly referred to as 'species') that are 
known to be cultivated (i.e. primarily as ornamental plants) in Southern Africa (Fig. 1a) was extracted from the 'Cultivated Plants of Southern Africa' (Glen 2002). The checklist contains over 8000 plant names and also includes some information on species' geographic origins. While the inclusion of a species in the checklist means that it has been introduced at least once for cultivation in at least one of the 10 countries in Southern Africa, it does not provide data on which of those countries it was introduced to. Although Glen (2002) does not claim to be exhaustive, it is the most comprehensive list of cultivated plants available for this region. The list also includes cultivars, but for those we only kept their species or infraspecific taxon names.

To align the list of cultivated plants with other datasets used in this study, we harmonized the taxonomic names according to The Plant List (ver. 1.1; <www.theplantlist. org >, accessed May 2019) using the R package 'Taxonstand' (Cayuela et al. 2019). We removed all non-seed plants (i.e. ferns and their allies, 114 species) from the final list, because data on their naturalization success are less complete. The final list included 6912 cultivated species of which 1595 are native to Southern Africa and 5317 are alien.

To identify which of the cultivated plants are currently naturalized in Southern Africa, we used the Global Naturalized Alien Flora (GloNAF) database (van Kleunen et al. 2019; accessed February 2020). GloNAF includes data on more than 13000 vascular plant taxa and their naturalization status in over 1000 regions around the globe (van Kleunen et al. 2019). From GloNAF, we extracted the naturalized species of all 10 Southern African countries (Fig. 1a).

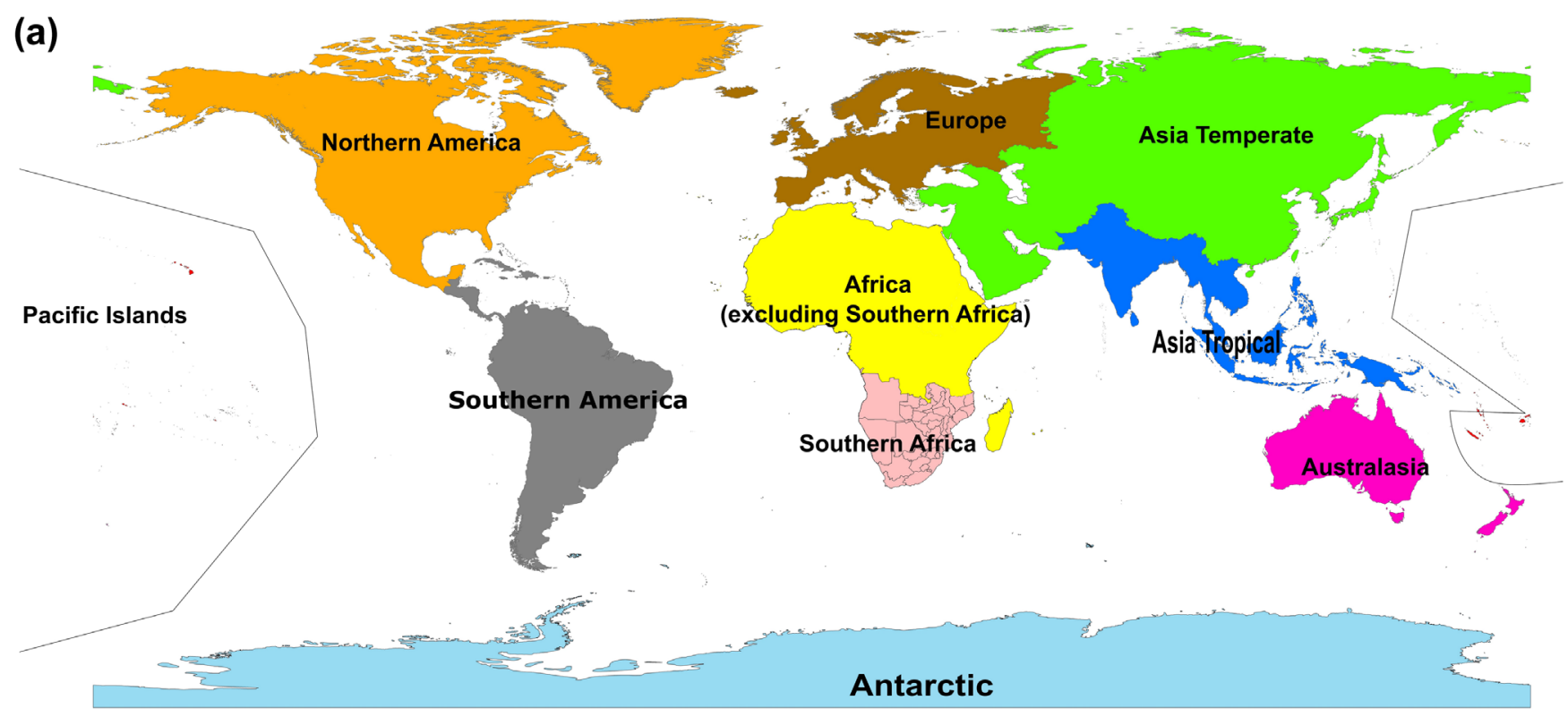

(b)

Pacific Islands

足

Asia Tropical

Africa (excluding Southern)

Northern America

Southern America

Asia Temperate

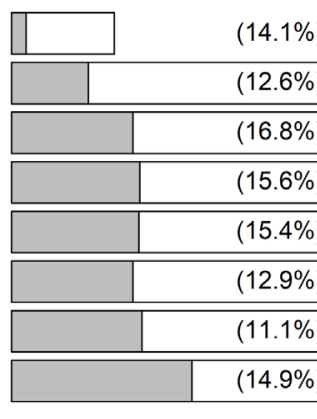

$(14.1 \%)$

0

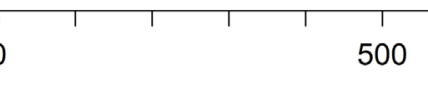

500

\section{Number of species}

Figure 1. Donor continents of the introduced and naturalized cultivated floras of Southern Africa. (a) The 9 TDWG continents and the 10 Southern African countries: Angola, Botswana, Eswatini, Lesotho, Malawi, Mozambique, Namibia, South Africa, Zambia and Zimbabwe (our study region). (b) Numbers of introduced cultivated plant species in Southern Africa according to their continents of origin. The cultivated species that have become naturalized are indicated in grey. Numbers in parentheses are percentages of cultivated species that have naturalized. As none of the introduced cultivated species is native to Antarctica, this continent is not included in $b$. 


\section{Data on geographic origin and species characteristics}

For the cultivated alien flora, Glen (2002) provides some information on the regions of origin. However, as this information may not be complete, we collected additional native range data from the Germplasm Resources Information Network (GRIN; <https://ars-grin.gov>), the World Checklist of Selected Plant Families (WCSP; <http://apps. kew.org/wcsp $>$ ) and the Plants of the World Online database (POWO 2019); <www.plantsoftheworldonline.org/>). As continents of origin, we used the nine level-1 regions of the World Geographical Scheme for Recording Plant Distributions of the Taxonomic Databases Working Group (TDWG; Brummitt 2001). A species can be native to more than one continent, and therefore the sum of the proportional representation of the origins exceeds one (Fig. 2). Native origin information was available for 269120 of the 303404 species (88.7\%) in the global flora outside of Southern Africa and for all 5317 introduced cultivated species in our dataset. As an estimate of native range size, we used the number of TDWG level-2 regions ( $\mathrm{n}=52$, Supporting information) each introduced cultivated species is native to (Maurel et al. 2016, Razanajatovo et al. 2016). This information was available for 269071 of the 303404 species (88.6\%) in the global flora outside of Southern Africa and for 5067 of the 5317 (95.3\%) introduced cultivated species in our dataset. As no species was introduced to Southern Africa from Antarctica, we did not consider this continent in our analyses.

To test whether the introduced and naturalized cultivated floras of Southern Africa are biased with regard to growth form (i.e. whether some growth forms are more or less frequent than expected by chance), we collected growth-form data from multiple sources. As these sources use different growth-form schemes, we harmonized them to seven standard categories: short-lived (i.e. annual or biennial), freestanding herb, long-lived free-standing herb, free-standing woody, aquatic, climber, epiphyte and parasite (note that a species can belong to more than one category; see Supporting information for more details). We found such data for 204 100 of the 303404 species $(67.3 \%)$ in the global flora outside of Southern Africa and for 4708 of the 5317 (88.5\%) introduced cultivated species.

For functional traits, there is less complete data for the global flora than there is for continent of origin, native range size and growth form. Therefore, we only analyzed whether these traits are associated with the naturalization success of the introduced cultivated species (i.e. we did not compare them to the global flora). We chose specific leaf area, height and seed mass, because they are part of the leaf-height-seed

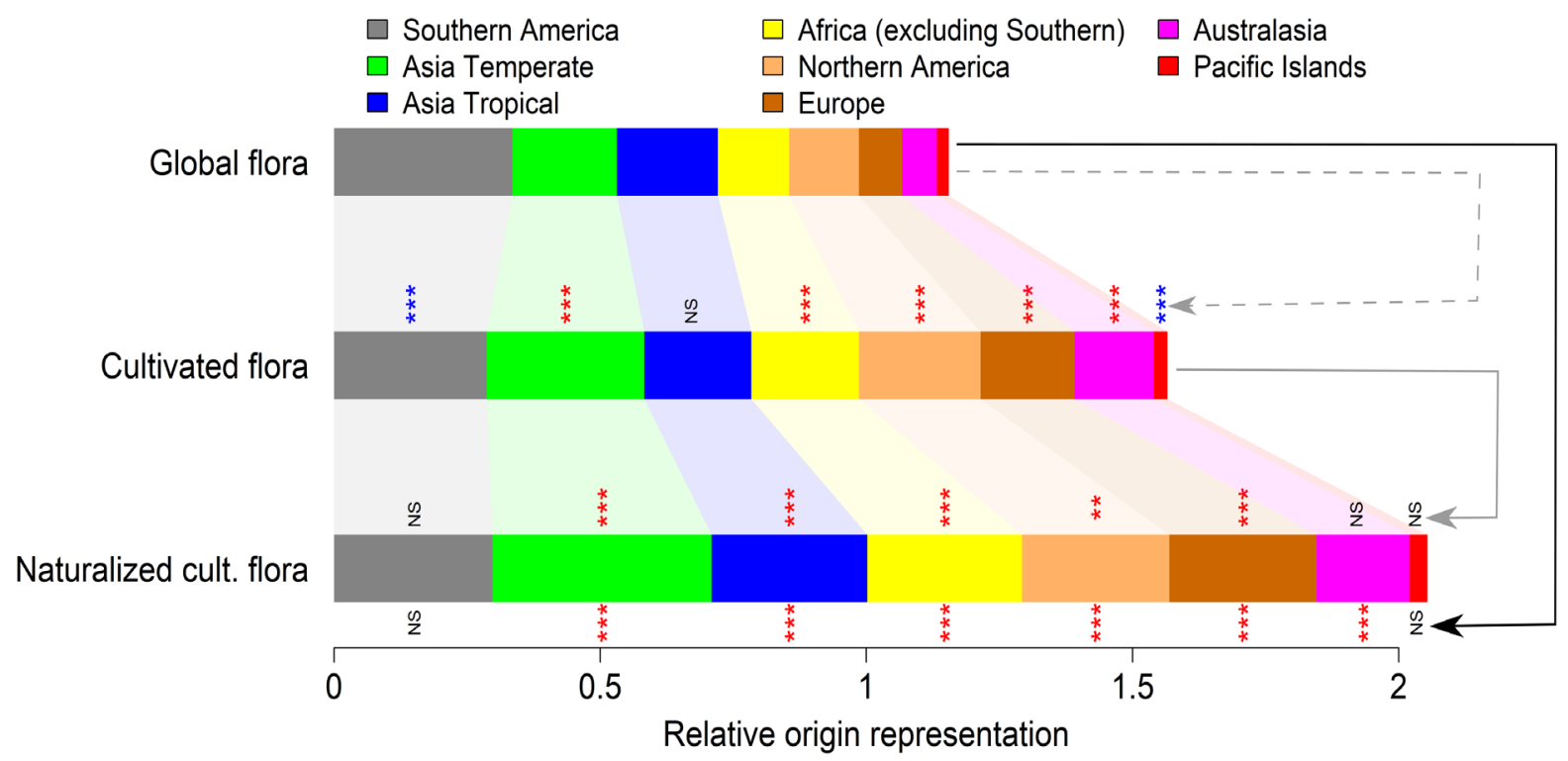

Figure 2. Relative representation of species native to different continents in the global flora and the introduced and naturalized cultivated floras of Southern Africa. The lighter colored connections between the stacked horizontal bars visualize which proportions increase, remain the same or decrease if one goes from the global flora, via the introduced cultivated flora, to the naturalized cultivated flora. Arrows represent the flows of species from the global flora to the introduced cultivated flora (grey dashed line) and naturalized flora (black solid line) and from the introduced cultivated flora of southern Africa to the naturalized flora (grey solid line). Asterisks below the stacked horizontal bars of the naturalized cultivated flora indicate whether the species flows from the respective continents are significantly over-represented (red) or underrepresented (blue) among the naturalized cultivated flora relative to the proportions in the global flora. Similarly, asterisks on the connections between the stacked bars indicate whether species from the respective continent are over- or underrepresented among the introduced cultivated flora relative to the global flora and among the naturalized cultivated flora relative to the introduced cultivated flora (Supporting information). Note that the cumulative proportions exceed one because species can be native to multiple continents. As none of the introduced cultivated species is native to Antarctica, this continent is not included in the figure. Another version of this figure that shows the proportion of species with missing origin data is provided in Supporting information. 
(LHS) plant-strategy scheme (Westoby 1998) and capture major variation in plant strategies (e.g. the acquisitiveconservative continuum; Diaz et al. 2016). Data on these traits were extracted from the TRY database (Zheng 1983, Wright et al. 2004, KEW 2008, 2014, Kleyer et al. 2008, Poorter et al. 2009, Wirth and Lichstein 2009, Kattge et al. 2020; Supporting information) and complemented with data from other sources (Supporting information). For the cultivated plants $(\mathrm{n}=5317)$, data on specific leaf area was available for 1607 (30.2\%) species, data on seed mass for 2895 $(54.4 \%)$ species and data on height for 3365 (63.3\%) species.

\section{Phylogenetic tree construction}

To assess phylogenetic biases among cultivated and naturalized plants in Southern Africa (i.e. whether species from certain clades are more likely to be cultivated and naturalized than expected by chance), we constructed a phylogenetic tree of the global seed-plant flora outside of Southern Africa (for more details Supporting information), including all seed plant species (also including infraspecific taxa) with accepted names in The Plant List $(n=303$ 404). In addition, for the analyses of the introduced cultivated flora of Southern Africa, we also constructed a phylogenetic tree for those 5317 species by pruning the global flora tree (Supporting information).

\section{Statistical analysis}

All statistical analyses were done in R, ver. 3.6.1 (<www.rproject.org $>$ ).

\section{Tests for biases in origins, native range size, growth form and phylogenetic composition}

To test for biases in geographic origins, native range size and growth forms of the introduced and naturalized cultivated floras of Southern Africa, we used randomization tests (Supporting information). These tests account for the fact that each species can be native to multiple continents and can have multiple growth forms. For each of those variables, we first created global source pools of species that are not native to Southern Africa. We did this separately for continent of origin, native range size and growth form (Supporting information) to maximize for each of them the number of species with available data. However, to assess how sensitive the results are towards these separate tests on partly different pools of species, we also did single randomization tests for all three variables jointly using only those 185805 (out of 303 404; 61.2\%) species with complete information for all three variables. The results of these single joint randomization tests are comparable to those of the separate tests (Supporting information).

Using the global source pools and the introduced and naturalized cultivated species lists, we did three types of comparisons (Supporting information). First, we tested whether the cultivated species introduced to Southern Africa are more or less likely to originate from a particular continent, to have a bigger or smaller native range size and to be more or less likely to belong to a particular growth form than expected by chance (i.e. when compared to the global flora outside of Southern Africa). Second, we tested this also for all naturalized cultivated species in Southern Africa, to assess which patterns we would find without accounting for introduction bias. Third, to account for introduction bias, we tested whether the naturalized cultivated species are a random subsample of the introduced cultivated flora of Southern Africa. For the first and second comparisons, we randomly drew 9999 times from the global source pools the number of introduced cultivated species with available data (5317, 5067 and 4708 for the continent-of-origin, native-range-size and growth-form tests, respectively), and the number of naturalized cultivated species (571, 565 and 541 for the continent-of-origin, native-range-size and growth-form tests, respectively), separately. For the third comparison, we used the introduced cultivated species of Southern Africa as species source pool and randomly drew from it 9999 times the number of species that have become naturalized and had available data (571, 565 and 541 for the continent-of-origin, native-range-size and growth-form tests, respectively). The observed proportions of introduced and naturalized cultivated species from each specific continent of origin, native range size or growthform category were then compared to the distributions of the corresponding random draws (i.e. the expected numbers of species). We considered the observed number to be smaller or greater than expected if it was in or beyond the lower 2.5\% or upper $2.5 \%$ of the distributions of random draws, respectively. In the randomization tests for the continent of origin and growth form, each test provides multiple p-values, one for each of the continents $(n=8)$ and growth-form categories $(n=7)$. Therefore, to correct for multiple testing, we adjusted the p-values according to the method of Benjamini and Hochberg (1995) for false discovery rates using the 'p.adjust' function in the $\mathrm{R}$ stats package.

To test if there is a phylogenetic bias in the composition of the introduced and naturalized cultivated floras, we again used a randomization test. We assessed whether the species within the subsets of introduced or naturalized cultivated species are more closely related (i.e. clustered), equally related or less closely related (i.e. overdispersed) than expected by chance (i.e. compared to a random subset of species from the global phylogeny). To test for phylogenetic clustering or overdispersion of the introduced and naturalized species, we first calculated Faith's phylogenetic diversity (PD) for each of these focal groups, which is a measure of the evolutionary history contained within a set of species and is calculated as the cumulative length of the branches connecting the taxa (Faith 1992). For each comparison, we then randomly drew 999 species subsets of the same number as in the focal group (introduced cultivated: $\mathrm{n}=5317$; naturalized cultivated: $\mathrm{n}=571$ ) from the global flora outside of Southern Africa and calculated PD for each subset. These randomizations provided distributions of expected $\mathrm{PD}$ values. We also compared the observed PD of naturalized cultivated species to the distribution of expected PD values calculated from 999 randomly drawn subsets of species from the phylogeny of cultivated 
species. Because the random subsets in a given comparison have the same number of species as the focal group and are drawn from the same phylogeny, this approach accounts for the fact that PD is influenced by both species richness as well as the structure of the underlying phylogeny (Tucker et al. 2017, Qian et al. 2021). Finally, we considered a focal group to be significantly phylogenetically clustered if the observed $\mathrm{PD}$ was below the 2.5th percentile of expected PD values and significantly overdispersed if above the 97.5 th percentile (Webb et al. 2002, Tucker et al. 2017, van Kleunen et al. 2020, Qian et al. 2021). We redid this analysis after merging all infraspecific taxa at the species level, and we found that the results are almost identical (Supporting information).

We report $p$-values from these analyses as the lower value out of the proportion of expected values either above or below the observed values; significant results are therefore associated with $\mathrm{p}<0.025$. As effect size for the deviation of the observed from the expected values (in all randomization tests), we calculated the standardized effect size (SES) as the difference between the observed number of species and the mean value of the distribution of expected values divided by the standard deviation of the expected values (Botta-Dukát 2018).

\section{Association of naturalization success with functional traits}

To test whether the naturalization success of introduced cultivated species in Southern Africa is associated with plant height, seed mass and specific leaf area, we used generalized linear models (GLMs) with a binomial error distribution and a logit link function. Multicollinearity was weak $(|\mathrm{r}| \leq 0.21$ for all combinations of explanatory variables; Supporting information). Nevertheless, we ran separate GLMs for each explanatory variable because combining the explanatory variables, each with many missing data, would reduce the sample size considerably. To test for potential non-linear relationships between naturalization success and explanatory variables, we also included a quadratic term for each explanatory variable after centering them to means of zero. Furthermore, to facilitate comparisons of the estimates within and between the models, we also scaled each explanatory variable to a standard deviation of one (Schielzeth 2010). Quadratic terms were removed when they were not significant. To account for phylogenetic non-independence between species, we also implemented a phylogenetically corrected GLM using the 'phyloglm' function of the R package 'phylolm', ver. 2.6 (Tung Ho and Ané 2014). However, because the results were very similar (Supporting information) and the standard binomial GLMs had the lowest AIC values, we only present the results of the latter. To compute the deviance explained $\left(\mathrm{R}^{2}\right)$ by the explanatory variables in our non-phylogenetic models, we calculated the Nagelkerke R² for each GLM (Nagelkerke 1991).

\section{Results}

The cultivated flora of Southern Africa (6912 species) represents $2.1 \%$ of the global seed plant flora (326 101 species). Although some of the cultivated species are native to
Southern Africa, 5317 species (77.0\%) have been introduced from elsewhere, and of those $571(10.7 \%)$ are naturalized in at least one region of Southern Africa.

\section{Patterns in geographic origin of introduced and naturalized cultivated plants}

The continent (i.e. TDWG level-1 region; Fig. 1a) that has donated the most species to the introduced cultivated flora of Southern Africa is Temperate Asia (29.6\%), followed by Southern America (28.6\%) and Northern America (22.8\%). Species originating from Temperate Asia (41.1\%) and Southern America (29.7\%) also compose the largest numbers of naturalized species, closely followed by other parts of Africa and by Europe and Northern America (Fig. 1b). The smallest donor of introduced and naturalized cultivated species - after Antarctica, which did not donate any - is the Pacific Islands region (134 and 19 species, respectively).

Continents that have donated significantly more species to the cultivated flora of Southern Africa than expected from their relative representation in the global flora are Northern America (standardized effect size $[\mathrm{SES}]=98.4, \mathrm{p}<0.001$ ), Europe (SES $=24.7, \mathrm{p}<0.001)$, Australasia $(\mathrm{SES}=24.0$, $\mathrm{p}<0.001)$, Temperate Asia $(\operatorname{SES}=16.5, \mathrm{p}<0.001)$ and Africa (excluding Southern Africa; SES $=12.4, \mathrm{p}<0.001$ ). On the other hand, the numbers of cultivated species from Southern America (SES $=-9.1, \mathrm{p}<0.001)$ and the Pacific Islands (SES $=-23.7, \mathrm{p}<0.001)$ were significantly lower than expected. The pattern for the naturalized cultivated flora of Southern Africa was overall very similar, as species from Northern America (SES $=10.7, \mathrm{p}<0.001$ ), Europe $(\mathrm{SES}=17.5, \mathrm{p}<0.001)$, Temperate Asia $(\mathrm{SES}=10.0, \mathrm{p}$ $<0.001)$, Africa $(\mathrm{SES}=10.8, \mathrm{p}<0.001)$ and Australasia $(\mathrm{SES}=9.7, \mathrm{p}<0.001)$ were significantly over-represented. However, the numbers of naturalized species from Southern America (SES $=-1.5, \mathrm{p}=0.085$ and the Pacific Islands $(\mathrm{SES}=1.5, \mathrm{p}=0.069)$ did not deviate significantly from expectation, and the number of species from Tropical Asia $(\mathrm{SES}=5.2, \mathrm{p}<0.001)$ was significantly higher than expected (Fig. 2, Supporting information).

When the geographic origins of naturalized species were compared to the origins of the cultivated flora of Southern Africa, species from Northern America $(S E S=2.8, p=0.0026)$, Europe $(\mathrm{SES}=5.5, \mathrm{p}<0.001)$, Temperate Asia $(\mathrm{SES}=6.3$, $\mathrm{p}<0.001)$, Tropical Asia $(\mathrm{SES}=5.8, \mathrm{p}<0.001)$ and Africa $(\mathrm{SES}=5.5, \mathrm{p}<0.001)$ were still significantly over-represented. However, in all native origins except Tropical Asia, the SES was lower than when compared to the global flora (Fig. 2, Supporting information). In other words, if one would not account for the introduction bias, the naturalization success of species from the different continents would be overestimated.

\section{Patterns in native range size of introduced and naturalized cultivated plants}

Compared to the global flora, the native range sizes of the introduced and naturalized cultivated floras were significantly 
larger than expected (introduced: $S E S=79.9, \mathrm{p}<0.001$; naturalized: $S E S=56.5, \mathrm{p}<0.001$; Fig. 3a-b). When the average native range size of the naturalized species was compared to that of the introduced cultivated flora of Southern Africa, it was still larger than expected $(\mathrm{SES}=16.7, \mathrm{p}<$ 0.001, Fig. 3a), but the SES was lower than when compared to the global flora.

\section{Phylogenetic patterns among introduced and naturalized cultivated plants}

Comparisons of the observed to the expected values of Faith's phylogenetic diversity revealed that both the introduced and naturalized cultivated species in Southern Africa are phylogenetically clustered subsets of the global seed-plant flora (introduced: $S E S=-22.5, \mathrm{p}<0.001$; naturalized: SES $=-10.0 \mathrm{p}<0.001$; Fig. 4a-b, Supporting information). The naturalized species are also a phylogenetically clustered subset of the cultivated species (SES $=-6.6, \mathrm{p}<0.001$ ) but less so than when compared to the global flora (Fig. 4a, Supporting information).

\section{Patterns in growth forms of introduced and naturalized cultivated plants}

Compared to the relative representation of different growth forms in the global flora, significantly more woody plants $(\mathrm{SES}=23.4, \mathrm{p}<0.001)$, short-lived herbs $(\mathrm{SES}=12.3$, $\mathrm{p}=0.001)$, epiphytes $(\mathrm{SES}=3.5, \mathrm{p}<0.001)$ and longlived herbs $(S E S=2.9, p=0.012)$ have been introduced for cultivation in Southern Africa than expected by chance. Parasitic plants (SES $=-9.7, \mathrm{p}<0.001)$, climbers

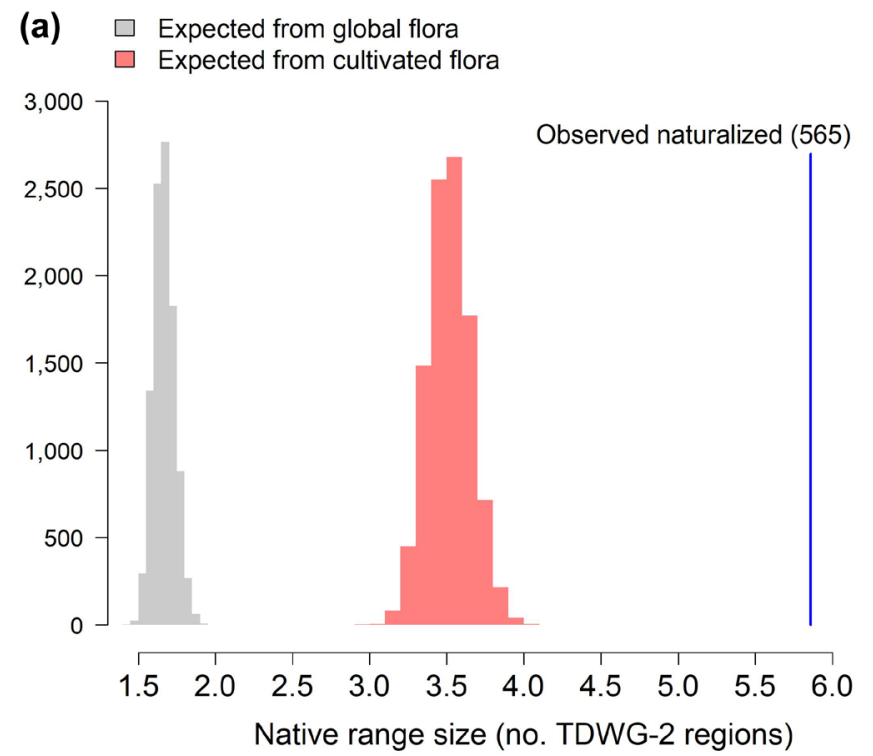

$(\mathrm{SES}=-3.3, \mathrm{p}=0.005)$ and aquatic plants $(\mathrm{SES}=-1.9$, $p=0.012$ ), on the other hand, were underrepresented. Likewise, in the naturalized cultivated flora, woody plants $(\mathrm{SES}=8.8, \mathrm{p}<0.001)$ and short-lived herbs $(\mathrm{SES}=24.7$, $\mathrm{p}<0.001)$ were over-represented, and parasitic plants $(\mathrm{SES}=-3.7, \mathrm{p}<0.001)$ were underrepresented. In addition, epiphytes (SES $=-7.7, \mathrm{p}<0.001)$ were also significantly underrepresented, but aquatic plants, climbers and long-lived herbs did not deviate from the expected numbers (Fig. 5, Supporting information).

When comparing relative representations of the different growth forms in the naturalized flora with those of the cultivated flora, only short-lived herbs $(\mathrm{SES}=17.2, \mathrm{p}<0.001)$ were still significantly over-represented, but woody plants were not (Fig. 5, Supporting information).

\section{Associations of functional traits with the naturalization of cultivated plants}

Among the cultivated flora of Southern Africa, the probability of naturalization increased with specific leaf area of the species (GLM: $Z=2.91, \mathrm{p} \leq 0.003$; Fig. 6a, Supporting information). Furthermore, the probability of naturalization was non-linearly related to seed mass and height of the plants, with the highest naturalization probability at intermediate seed mass $(Z=-3.62, p<0.001$; Fig. 6b; see Supporting information) and intermediate height $(Z=-2.16, p<0.035$; Fig. 6b-c; Supporting information). However, the amount of explained variation by these models was very small (all Nagelkerke $\mathrm{R}^{2}<0.01$; Supporting information).

(b)

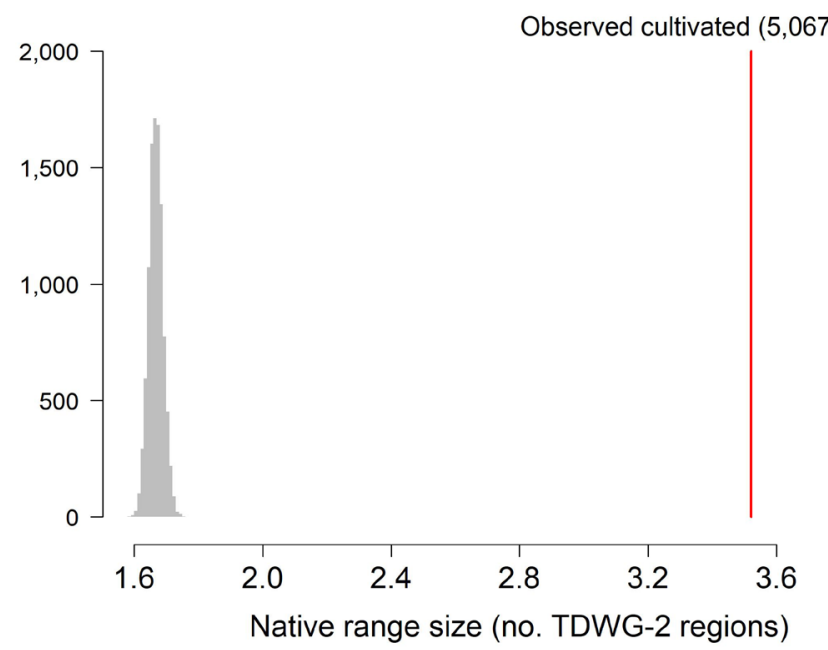

Figure 3. Biases in native range size of the introduced and naturalized cultivated floras of Southern Africa. (a) The observed average native range size of the naturalized cultivated flora of Southern Africa (blue vertical line) relative to expectations based on the global flora (grey histogram) and the introduced cultivated flora (red histogram). (b) The observed average native range size of the introduced cultivated flora of Southern Africa (red line) relative to expectations based on the global flora (grey histogram). The histograms of the expected average native range size are based on 9999 random draws of the same number of species as found in the naturalized flora (a) and in the cultivated flora (b) from the respective reference floras. 

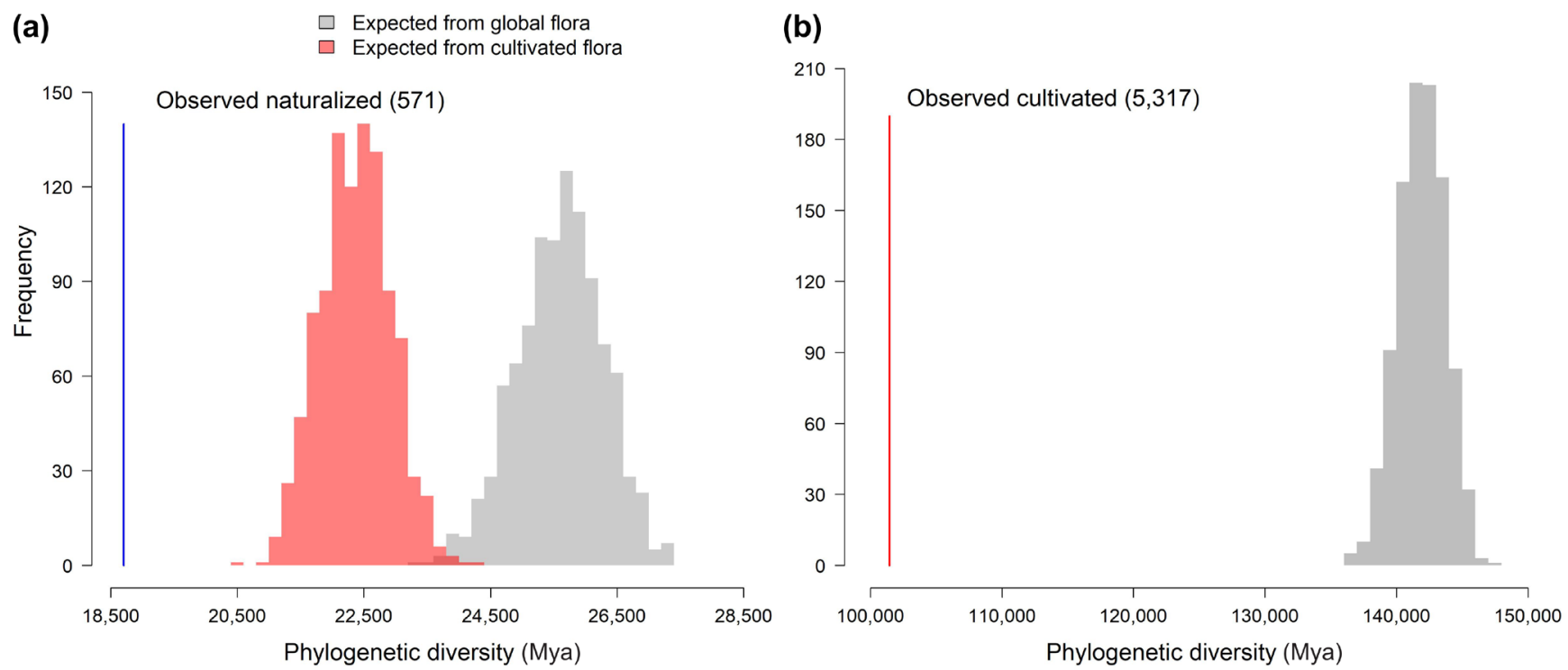

Figure 4. Phylogenetic clustering of the introduced and naturalized cultivated floras of Southern Africa. (a) Phylogenetic diversity of the naturalized cultivated flora of Southern Africa (blue vertical lines) relative to expectations based on the global flora (grey histogram) and introduced cultivated flora (red histogram), repectivelly. (b) Phylogenetic diversity of the introduced cultivated flora of Southern Africa (red line) relative to expectations based on the global flora (grey histogram). The histograms of expected phylogenetic diversities are based on 999 random draws of the same number of species as in the naturalized flora (a) and cultivated flora (b) from the respective reference floras. If the observed phylogenetic diversity is smaller than the expected values, this indicates phylogenetic clustering.

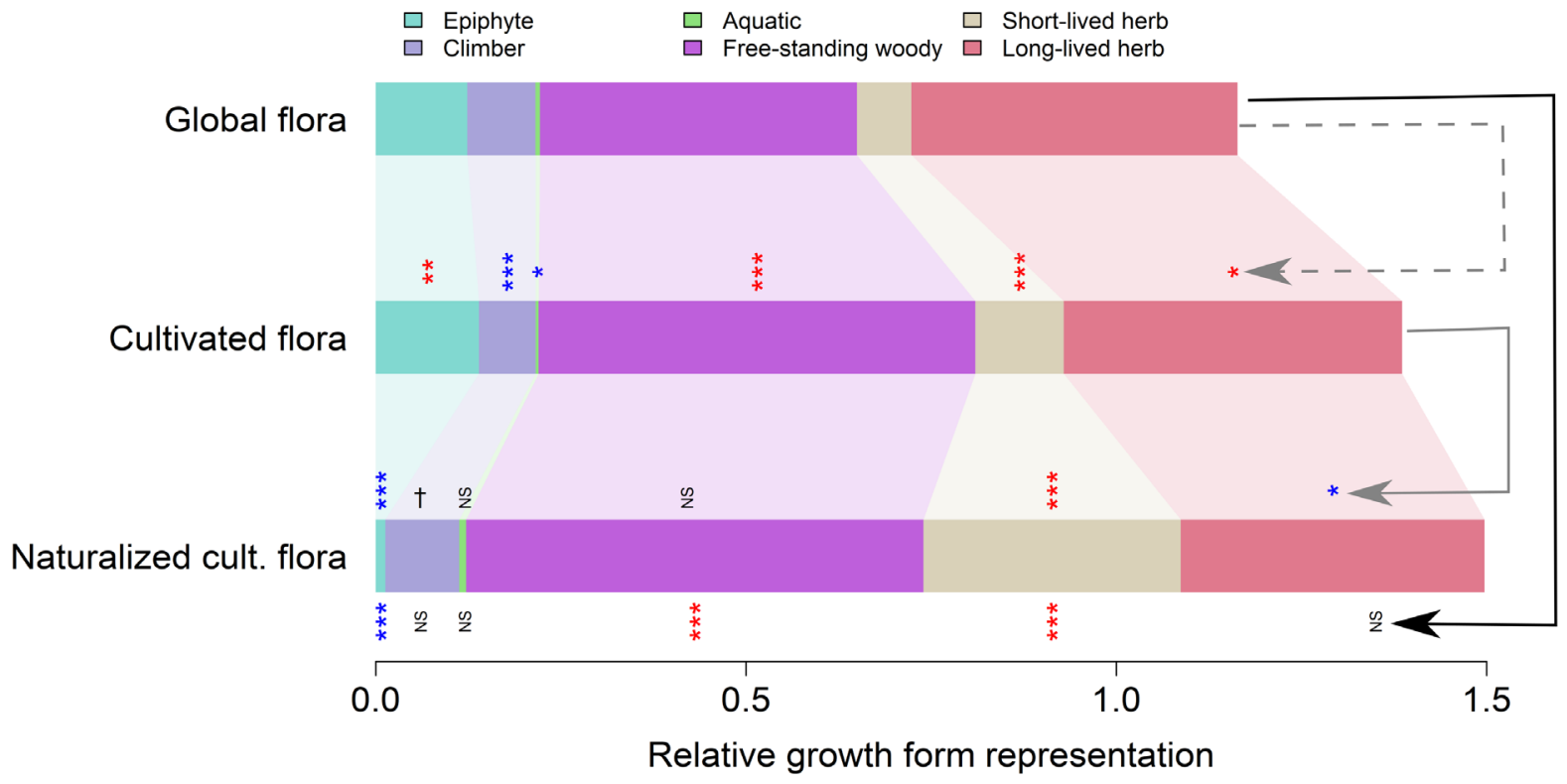

Figure 5. Relative representation of species with different growth forms for the global flora and the introduced and naturalized cultivated floras of Southern Africa. The lighter colored connections between the stacked horizontal bars indicate whether the proportions increase, remain the same or decrease if one goes from the global flora, via the introduced cultivated flora, to the naturalized cultivated flora. Arrows represent the flows of species from the global flora to the introduced cultivated flora (grey dashed line) and naturalized flora (black solid line), and from the introduced cultivated flora of southern Africa to the naturalized flora (grey solid line). Asterisks below the stacked horizontal bars of the naturalized cultivated flora indicate whether species with different growth forms are significantly over-represented (red) or underrepresented (blue) among the naturalized flora relative to the proportions in the global flora. Similarly, asterisks on the connections between the stacked bars indicate whether species with the respective growthforms are over- or underrepresented among the introduced cultivated flora relative to the global flora, and among the naturalized cultivated flora relative to the introduced cultivated flora (Supporting information). Note that the cumulative proportions exceed one because some species can take on more than one growth form. The parasitic plants are not shown as they are a very small fraction of the global flora. Another version of this figure that shows the proportion of species with missing growth-form data is provided in Supporting information. 
(a)

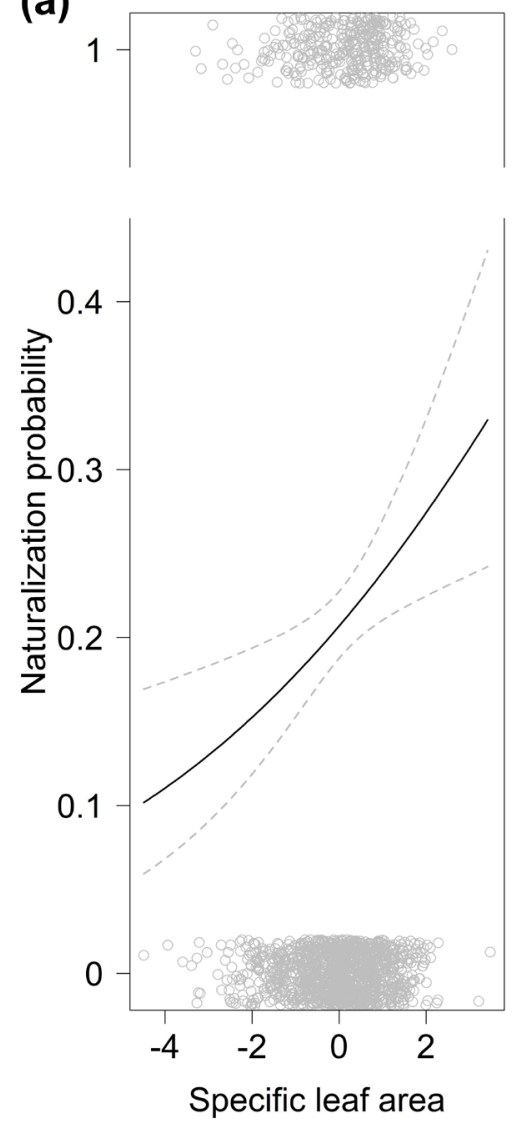

(b)
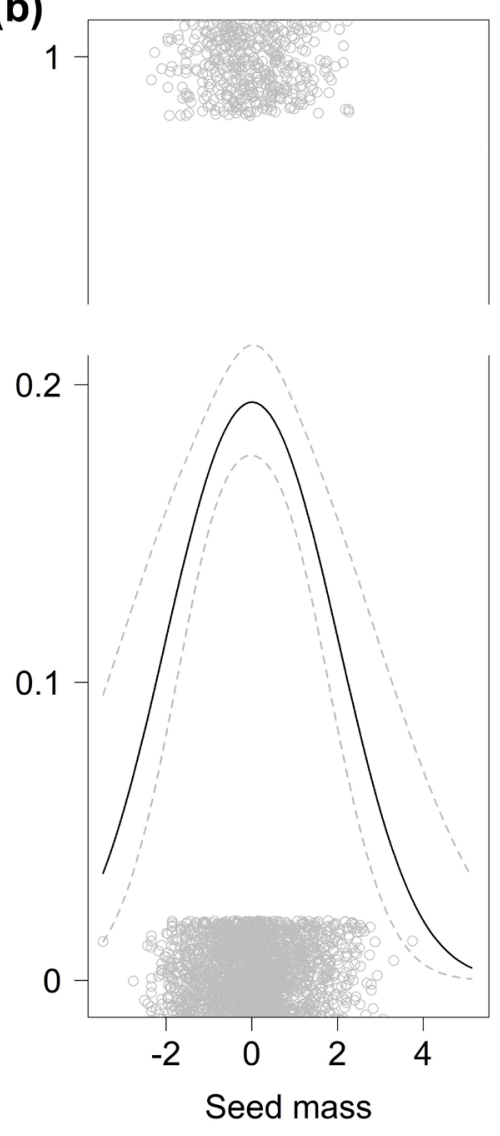

(c)
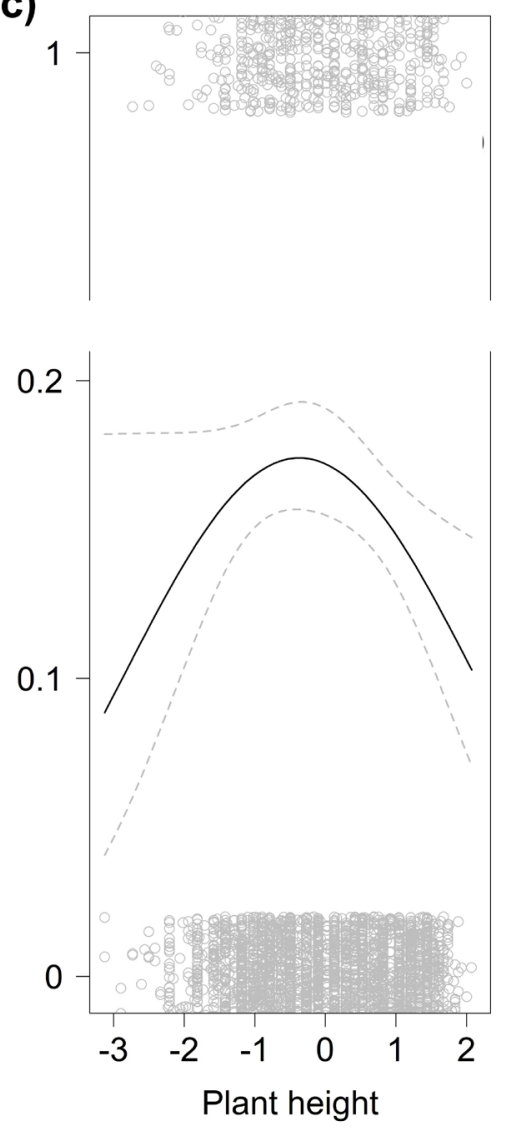

Figure 6. Naturalization of introduced cultivated alien plants in Southern Africa in relation to (a) specific leaf area, (b) individual seed mass and (c) plant height. The solid lines are the predicted relationships from binomial GLMs (Supporting information), and the dashed lines indicate the 95\% CIs. The results of phylogenetic binomial GLMs were very similar to those of the standard binomial GLMs (Supporting information). The values of the functional traits of the naturalized and non-naturalized species are shown as points at one and zero, respectively (jittered to increase visibility). The values of the traits were standardized to a mean of zero and a standard deviation of one.

\section{Discussion}

By comparing the cultivated flora of Southern Africa to the global flora, our study quantified introduction biases and their implications for studying some of the drivers of naturalization success. We showed that the species that humans have introduced for cultivation in Southern Africa do not represent a random subset of the global flora. They are biased with regard to their continent of origin, native range size, growth form and phylogenetic composition. In some cases, the characteristics that were associated with the introduction of species for cultivation also increased the probability of subsequent naturalization of those species. In other cases, patterns in characteristics of naturalized species were entirely determined by introduction biases. However, we were also able to identify naturalization-success attributes that were otherwise hidden by introduction biases. So, patterns in origin, growth form, phylogenetic composition and functional traits of naturalized species may largely reflect biases in the species that humans chose to introduce for cultivation, and this needs to be accounted for when associating plant characteristics with naturalization success.

\section{Patterns in geographic origin and native range size}

We showed that continents vary in their contributions to the introduced and naturalized cultivated floras of Southern Africa. In a previous global analysis, it was shown that in the naturalized flora of the African continent, as well as in the naturalized floras of most other continents, alien species from Africa, Europe, Northern America and Temperate Asia are over-represented (van Kleunen et al. 2015a). Similarly, we here found that these continents are also over-represented as donors of the naturalized cultivated flora and that in addition plants from Australasia and Tropical Asia are over-represented. Interestingly, the over-representation of Australasian species in the naturalized flora is completely accounted for by a higher than expected probability of introduction. In other words, Australasian species do not have higher naturalization probabilities once introduced. On the other hand, Tropical Asian species were not more likely to be introduced but have a higher naturalization probability once introduced. This suggests that species from Tropical Asia may have an innate higher naturalization potential in Southern Africa. 
In absolute terms, Southern America has donated the second largest number of species to the cultivated flora of Southern Africa. However, relative to its enormous native plant-species richness, Southern America is underrepresented in the cultivated flora. This might reflect that for the majority of Southern American species, and particularly for those from the tropical parts, the climate in Southern Africa is not suitable for cultivation. The Southern American flora, however, is also disproportionally underrepresented as a donor of economic plants globally (van Kleunen et al. 2020). The same is true for the Pacific Islands, which is also disproportionally underrepresented in the cultivated flora of Southern Africa (Fig. 2). This could reflect that many of the Pacific Island plant species are island endemics (Kier et al. 2009) and that, due to their restricted ranges and isolation of the islands, they had less chance to be prospected for cultivation.

The high naturalization success of plants from Africa, Europe and Temperate Asia could reflect that many of them are from the Mediterranean, and thus find climatically suitable areas in Southern Africa (Peel et al. 2007). However, climatic similarity cannot fully explain naturalization success, as species from other continents with climates similar to Southern Africa, such as Australasia, are underrepresented among naturalized species. Possibly the higher naturalization probability of plants from certain continents could also be explained by higher planting frequencies (i.e. propagule pressur; Lockwood et al. 2005, Colautti et al. 2006) or an earlier introduction. However, as data on planting frequencies and year of introduction are not available for the species in our dataset, we could not test this.

We found that naturalization success in Southern Africa was positively associated with native range size. This is also evident from the fact that in Fig. 2 the sum of the relative representations of species native to the different continents increased from the global flora, via the introduced cultivated flora, to the naturalized cultivated flora. In other words, species native to multiple continents (indicative of a large native range size) are more likely to be introduced for cultivation and to subsequently naturalize. Our finding provides further evidence that native range size is positively associated with invasion success (Scott and Panetta 1993, Goodwin et al. 1999, Prinzing et al. 2002, Maurel et al. 2016, Razanajatovo et al. 2016), but see Milbau and Stout (2008) for an exception. Both introduction and naturalization may be positively associated with native range size because species with large ranges are more likely to be prospected for cultivation and to be introduced more frequently (i.e. have a higher propagule pressure). Moreover, species with large native ranges could be ecologically and genetically more versatile and have traits that allow them to easily establish (Pyšek et al. 2009).

\section{Phylogenetic patterns}

In a global analysis, Pyšek et al. (2017) showed that some plant families have more and others have fewer naturalized species than expected based on their species richness. Therefore, it is not surprising that we found a strong phylogenetic clustering for the naturalized plants in Southern Africa. However, we also found that there was strong phylogenetic clustering of the introduced cultivated flora of Southern Africa, and that the phylogenetic clustering of naturalization was weaker when compared to the cultivated flora instead of to the global flora. This indicates that a considerable proportion of the phylogenetic pattern in naturalization success is due to an introduction bias. A similar result was recently found in an analysis of the naturalization success of economic plants in the extant global seed flora (van Kleunen et al. 2020). Nevertheless, the phylogenetic clustering of naturalization among cultivated plants was still highly significant. This indicates that naturalization ability is phylogenetically clustered, possibly because some phylogenetically conserved characteristics that are shared among closely related species promote naturalization success (Pyšek and Richardson 2007, van Kleunen et al. 2010, 2015b).

\section{Patterns in species traits}

We found evidence that some growth forms were disproportionally over-represented and others were underrepresented in the introduced and naturalized cultivated floras of Southern Africa. As was the case for geographic origin and phylogeny, this pattern in the naturalized flora was partly driven by introduction biases. South Africa has been called the 'world capital of tree invasions' (Richardson et al. 2020), and our study confirms that free-standing woody species constitute the largest growth-form category among the naturalized cultivated species. Importantly, however, our study also shows that woody species were only over-represented among naturalized plants because they were more likely to be introduced. Due to a paucity of native trees suitable for timber production, many woody species have been introduced to Southern Africa for forestry plantations and also for environmental purposes such as the provisioning of shade and stabilization of sand dunes (Richardson et al. 2003, 2020, van Wilgen et al. 2020). The short-lived herbs, on the other hand, were both more likely to be introduced and to naturalize following introduction.

Among the introduced cultivated flora, we found significant relationships between naturalization probability and the functional traits seed mass, height and specific leaf area. However, despite the statistical significance of the relationships, the amount of variation in naturalization success explained was very low. This most likely reflects that also many other traits and extrinsic factors affect naturalization success. Although most studies only consider linear effects of species traits, we found evidence that naturalization success was highest for cultivated plants with intermediate values of seed mass and plant height. While very small seeds might not contain sufficient resources to warrant seedling survival in stressful environments, very large seeds might have limited dispersal ability and are produced in low numbers (Westoby et al. 1992, Kempel et al. 2013). With regard to plant height, although a short stature might be beneficial in stressful low-resource environments, tall stature increases 
competitive ability as well as seed dispersal (Moles et al. 2009). However, very tall species may not be successful in Southern Africa due to their high water requirements. In contrast to seed mass and height, specific leaf area showed a positive association with naturalization success. While the benefits of low and high specific leaf area are also likely to depend on the habitat, many studies have found that invasion success is associated with high specific leaf area (Pyšek and Richardson 2007, van Kleunen et al. 2010). This might be because specific leaf area is indicative of fast growth (Lambers and Poorter 1992). Although Southern Africa has many habitats that are poor in nutrients or water, where fast growth might not be advantageous, invasions are still most likely to start in sites that happen to be richer in resources, where fast growth is advantageous. So, while the overall contributions of the three functional traits to naturalization success appear to be negligible, they are at least to a certain degree related to the naturalization probability of cultivated plants and illustrate the need to test for non-linearity in similar relationships in future work.

\section{Missing data implications}

Our study tests how introduced species deviate from the global flora with regard to native origin, native range size and growth form. However, it is important to note that the introduction biases we observed are contingent on the assumption that the global flora outside of Southern Africa 303404 species) is well represented by the species for which we found data on native origin $(88.7 \%)$, native range size $(88.6 \%)$ and growth form $(67.3 \%)$. Missing data in plant traits is usually not completely random (Sandel et al. 2015, Cornwell et al. 2019, König et al. 2019, Kattge et al. 2020). Indeed, the species with missing data in our global flora appear to be phylogenetically clustered (Supporting information). However, most of the species with missing data were not introduced for cultivation in Southern Africa and did not naturalize (Supporting information), reflecting that cultivated and naturalized species are better studied than the ones that are not. So, our results for the transition from introduced to naturalized will hardly be affected by the missing data.

How our estimates of introduction bias are affected by missing data is difficult to say. With regard to native origin, we assume that most of the species with missing data are from continents with less comprehensive biodiversity data (i.e. Africa, Asia and South America; Meyer et al. 2016). Our analyses may therefore overestimate the representation of species originating from these continents in the cultivated flora of South Africa. Most of the species with missing native range size data are likely rare species that have restricted ranges. This would imply that the over-representation of species with large native range sizes among cultivated species is even larger than we estimated. Similarly, we assume that most of the world's woody species, and trees in particular (Beech et al. 2017), have been well described. This would imply that the over-representation of free-standing woody species among cultivated species is even larger than we estimated, and that the other growth form groups might be less strongly over-represented or more strongly underrepresented than we estimated. As the availability of data on distributions and characteristics of species is rapidly increasing (Weigelt et al. 2020), missing data should become less of a problem for future studies on introduction biases.

\section{Conclusions}

We showed that there are strong patterns in the geographic origin, phylogeny and species characteristics of the introduced cultivated flora of Southern Africa. Although these biases do not explain all patterns of the naturalized flora, they contribute significantly to these patterns. For example, while Australasian species are disproportionally over-represented among naturalized cultivated plants, this is solely because a disproportionally high number of Australasian species has been introduced to Southern Africa. Similarly, the large number of naturalized free-standing woody species is due to a disproportionally high number of woody species that have been introduced. On the other hand, certain groups of species, such as those introduced from Tropical Asia and climbers, might show weak naturalization success when compared to the global flora, although they have disproportionally high naturalization success once introduced. We further showed that among the introduced cultivated plants of Southern Africa, naturalization success is related to functional traits (i.e. seed mass, height and specific leaf area). Importantly, such relationships can be non-linear, with the highest naturalization success for species with intermediate seed masses and heights. Overall, our case study for Southern Africa does not only show that it is important to account for introduction biases but also to quantify the biases. Therefore, we emphasize the need to collate data not only on those species that have become naturalized but also on the ones that have been introduced for cultivation and have not yet become naturalized.

Acknowledgements - We thank C. Gommel, K. Mamonova, V. Pasqualetto and B. Rüter for help with data extraction, and Lesley Henderson for providing lists of naturalized species for South Africa. Funding - AO thanks the Ministry of Higher Education of Sudan and the University of Konstanz for funding and support from the International Max Planck Research School for Organismal Biology. MvK thanks the German Research Foundation DFG for funding (grants 264740629 and 432253815). FE acknowledges funding by the Austrian Science Foundation FWF (grant I 3757-B29). PP and JP were supported by EXPRO grant no. 19-28807X (Czech Science Foundation) and long-term research development project RVO 67985939 (Czech Academy of Sciences).

Conflict of interest - No conflicts of interest to disclose.

\section{Author contributions}

Ali Omer: Conceptualization (equal); Data curation (lead); Formal analysis (lead); Methodology (lead); Visualization (lead); Writing - original draft (lead); Writing - review and editing (lead). Trevo Fristoe: Formal analysis (equal); 
Methodology (equal); Visualization (equal); Writing - original draft (equal); Writing - review and editing (equal). Qiang Yang: Methodology (supporting); Writing - original draft (supporting); Writing - review and editing (supporting). Noëlie Maurel: Data curation (supporting); Writing - original draft (supporting); Writing - review and editing (supporting). Patrick Weigelt: Data curation (supporting); Writing - original draft (supporting); Writing - review and editing (supporting). Holger Kreft: Data curation (supporting); Writing - original draft (supporting); Writing - review and editing (supporting). Jonas Bleilevens: Data curation (supporting); Writing - review and editing (supporting). Wayne Dawson: Writing - original draft (supporting); Writing - review and editing (supporting). Franz Essl: Writing original draft (supporting); Writing - review and editing (supporting). Jan Pergl: Writing - original draft (supporting); Writing - review and editing (supporting). Petr Pysek: Writing - original draft (supporting); Writing - review and editing (supporting). Mark van Kleunen: Conceptualization (equal); Data curation (equal); Formal analysis (equal); Methodology (equal); Supervision (lead); Visualization (equal); Writing - original draft (equal); Writing - review and editing (equal).

\section{Transparent Peer Review}

The peer review history for this article is available at $<$ https:// publons.com/publon/10.1111/ecog.05669>.

\section{Data availability statement}

Data are available from the Dryad Digital Repository: <https:// doi.org/10.5061/dryad.v6wwpzgwv> (Omer et al. 2021).

\section{References}

Ansong, M. et al. 2018. Naturalized and invasive alien flora of Ghana. - Biol. Invas. 21: 669-683.

Baker, H. G. 1965. Characteristics and modes of origin of weeds. - In: G. L. Stebbins (ed.), The genetics of colonizing species. Academic Press Inc., pp. 147-172.

Beech, E. et al. 2017. GlobalTreeSearch: the first complete global database of tree species and country distributions. - J. Sustain. For. 36: 454-489.

Benjamini, Y. and Hochberg, Y. 1995. Controlling the false discovery rate: a practical and powerful approach to multiple testing. - J. R. Stat. Soc. B 57: 289-300.

Blackburn, T. M. et al. 2011. A proposed unified framework for biological invasions. - Trends Ecol. Evol. 26: 333-339.

Botta-Dukát, Z. 2018. Cautionary note on calculating standardized effect size (SES) in randomization test. - Community Ecol. 19: 77-83.

Bradley, B. A. et al. 2012. Global change, global trade and the next wave of plant invasions. - Front. Ecol. Environ. 10: 20-28.

Brummitt, R. K. 2001. World geographical scheme for recording plant distributions. - Hunt Inst. for Botanical Documentation.

Bucharova, A. and van Kleunen, M. 2009. Introduction history and species characteristics partly explain naturalization success of
North American woody species in Europe. - J. Ecol. 97: 230-238.

Cadotte, M. W. et al. 2006. Ecological patterns and biological invasions: using regional species inventories in macroecology. - Biol. Invas. 8: 809-821.

Cayuela, L. et al. 2019. Taxonstand: taxonomic standardization of plant species names. - <https://CRAN.R-project.org/ package $=$ Taxonstand $>$.

Chrobock, T. et al. 2011. Introduction bias: cultivated alien plant species germinate faster and more abundantly than native species in Switzerland. - Basic Appl. Ecol. 12: 244-250.

Colautti, R. I. et al. 2006. Propagule pressure: a null model for biological invasions. - Biol. Invas. 8: 1023-1037.

Cornwell, W. K. et al. 2019. What we (don't) know about global plant diversity. - Ecography 42: 1819-1831.

Dawson, W. et al. 2009. Factors explaining alien plant invasion success in a tropical ecosystem differ at each stage of invasion. - J. Ecol. 97: 657-665.

Diaz, S. et al. 2016. The global spectrum of plant form and function. - Nature 529: 167-71.

Dodd, A. J. et al. 2015. The changing patterns of plant naturalization in Australia. - Divers. Distrib. 21: 1038-1050.

Faith, D. P. 1992. Conservation evaluation and phylogenetic diversity. - Biol. Conserv. 61: 1-10.

Faulkner, K. T. et al. 2016. Understanding and managing the introduction pathways of alien taxa: South Africa as a case study. Biol. Invas. 18: 73-87.

Faulkner, K. T. et al. 2020. South Africa's pathways of introduction and dispersal and how they have changed over time. - In: van Wilgen, B. W. et al. (eds), Biological invasions in South Africa. Springer International Publishing, pp. 313-354.

Fristoe, T. et al. 2021. Dimensions of invasiveness: links between abundance, geographic range size and habitat breadth in Europe's alien and native floras. - Proc. Natl Acad. Sci. USA 118: e2021173118.

Gippet, J. M. W. and Bertelsmeier, C. 2021. Invasiveness is linked to greater commercial success in the global pet trade. - Proc. Natl Acad. Sci. USA 118: e2016337118.

Glen, H. F. 2002. Cultivated plants of Southern Africa: botanical names, common names, origins, literature. - National Botanical Inst., Jacana.

Goodwin, B. J. et al. 1999. Predicting invasiveness of plant species based on biological information. - Conserv. Biol. 13: 422-426.

Haeuser, E. et al. 2018. European ornamental garden flora as an invasion debt under climate change. - J. Appl. Ecol. 55: 2386-2395.

Hamilton, M. A. et al. 2005. Life-history correlates of plant invasiveness at regional and continental scales. - Ecol. Lett. 8: 1066-1074.

Hulme, P. E. et al. 2008. Grasping at the routes of biological invasions: a framework for integrating pathways into policy. - J. Appl. Ecol. 45: 403-414.

Kattge, J. et al. 2020. TRY plant trait database - enhanced coverage and open access. - Global Change Biol. 26: 119-188.

Kempel, A. et al. 2013. Determinants of plant establishment success in a multispecies introduction experiment with native and alien species. - Proc. Natl Acad. Sci. USA 110: 12727-32.

KEW 2008, 2014. Seed information database (SID). - <http:// data.kew.org/sid/>, accessed May 2020.

Kier, G. et al. 2009. A global assessment of endemism and species richness across island and mainland regions. - Proc. Natl Acad. Sci. USA 106: 9322-9327. 
Kleyer, M. et al. 2008. The LEDA Traitbase: a database of lifehistory traits of the northwest European flora. - J. Ecol. 96: 1266-1274.

König, C. et al. 2019. Biodiversity data integration - the significance of data resolution and domain. - PLoS Biol. 17: e3000183.

Kueffer, C. et al. 2013. Integrative invasion science: model systems, multi-site studies, focused meta-analysis and invasion syndromes. - New Phytol. 200: 615-633.

Küster, E. C. et al. 2008. Trait interactions help explain plant invasion success in the German flora. - J. Ecol. 96: 860-868.

Lambdon, P.-W. et al. 2008. Alien flora of Europe: species diversity, temporal trends, geographical patterns and research needs. Preslia-Praha 80: 101-149.

Lambers, H. and Poorter, H. 1992. Inherent variation in growthrate between higher-plants - a search for physiological causes and ecological consequences. - Adv. Ecol. Res. 23: 187-261.

Lewis, S. L. and Maslin, M. A. 2015. Defining the Anthropocene. - Nature 519: 171-180.

Liao, H. et al. 2021. Different functional characteristics can explain different dimensions of plant invasion success. - J. Ecol. 109: $1524-1536$.

Lockwood, J. L. et al. 2005. The role of propagule pressure in explaining species invasions. - Trends Ecol. Evol. 20: 223-228.

Maurel, N. et al. 2016. Introduction bias affects relationships between the characteristics of ornamental alien plants and their naturalization success. - Global Ecol. Biogeogr. 25: 1500-1509.

McGregor, K. F. et al. 2012. What determines pine naturalization: species traits, climate suitability or forestry use? - Divers. Distrib. 18: 1013-1023.

Meyer, C. et al. 2016. Multidimensional biases, gaps and uncertainties in global plant occurrence information. - Ecol. Lett. 19: 992-1006.

Milbau, A. and Stout, J. C. 2008. Factors associated with alien plants transitioning from casual, to naturalized, to invasive. Conserv. Biol. 22: 308-317.

Moles, A. T. et al. 2009. Global patterns in plant height. - J. Ecol. 97: 923-932.

Moodley, D. et al. 2013. Different traits determine introduction, naturalization and invasion success in woody plants: Proteaceae as a test case. - PLoS One 8: e75078.

Nagelkerke, N. J. D. 1991. A note on a general definition of the coefficient of determination. - Biometrika 78: 691-692.

Omer, A. et al. 2021. Characteristics of the naturalized flora of Southern Africa largely reflect the non-random introduction of alien species for cultivation. - Dryad Digital Repository, <https://doi.org/10.5061/dryad.v6wwpzgwv>.

Ordonez, A. et al. 2010. Functional differences between native and alien species: a global-scale comparison. - Funct. Ecol. 24: 1353-1361.

Palma, E. et al. 2021. Introduction bias: imbalance in species introductions may obscure the identification of traits associated with invasiveness. - bioRxiv 10.1101/2021.03.22.436397.

Peel, M. C. et al. 2007. Updated world map of the Koppen-Geiger climate classification. - Hydrol. Earth Syst. Sci. 11: 1633-1644.

Pergl, J. et al. 2016. Dark side of the fence: ornamental plants as a source of wild-growing flora in the Czech Republic. - Preslia 88: $163-184$.

Poorter, H. et al. 2009. Causes and consequences of variation in leaf mass per area (LMA): a meta-analysis. - New Phytol. 182: $565-588$.
POWO 2019. Plants of the world online. - Facilitated by the Royal Botanic Gardens, Kew. Published on the Internet; <www.plantsoftheworldonline.org/>, accessed 10-26 August 2020.

Prinzing, A. et al. 2002. Which species become aliens? - Evol. Ecol. Res. 4: 385-405.

Pyšek, P. and Richardson, D. M. 2007. Traits associated with invasiveness in alien plants: where do we stand? - In: Nentwig, W. (ed.), Biological invasions. Springer, pp. 97-125.

Pyšek, P. et al. 2009. The global invasion success of central European plants is related to distribution characteristics in their native range and species traits. - Divers. Distrib. 15: 891-903.

Pyšek, P. et al. 2017. Naturalized alien flora of the world: species diversity, taxonomic and phylogenetic patterns, geographic distribution and global hotspots of plant invasion. - Preslia 89: 203-274.

Qian, H. et al. 2021. Evolutionary assembly of flowering plants into sky islands. - Nat. Ecol. Evol. 5: 640-646.

Razanajatovo, M. et al. 2016. Plants capable of selfing are more likely to become naturalized. - Nat. Commun. 7: 13313.

Reichard, S. H. and White, P. 2001. Horticulture as a pathway of invasive plant introductions in the United States. - Bioscience 51: 103-113.

Richardson, D. M. et al. 2000. Naturalization and invasion of alien plants: concepts and definitions. - Diversity 6: 93-107.

Richardson, D. M. et al. 2003. Vectors and pathways of biological invasions in South Africa - past, present and future. - In: Ruiz, G. M. and Carlton, J. T. (eds), Invasive species: vectors and management strategies. pp. 292-349.

Richardson, D. M. et al. 2020. The biogeography of South African terrestrial plant invasions. - In: van Wilgen, B. W. et al. (eds), Biological invasions in South Africa. Springer, pp. 67-96.

Sandel, B. et al. 2015. Estimating themissing species bias in plant trait measurements. - J. Veg. Sci. 26: 828-838.

Schielzeth, H. 2010. Simple means to improve the interpretability of regression coefficients. - Methods Ecol. Evol. 1: 103-113.

Scott, J. K. and Panetta, F. D. 1993. Predicting the Australian weed status of Southern African plants. - J. Biogeogr. 20: 87-93.

Tucker, C. M. et al. 2017. A guide to phylogenetic metrics for conservation, community ecology and macroecology. - Biol. Rev. 92: 698-715.

Tung Ho, L. S. and Ané, C. 2014. A linear-time algorithm for Gaussian and non-Gaussian trait evolution models. - Syst. Biol. 63: 397-408.

van Kleunen, M. et al. 2010. A meta-analysis of trait differences between invasive and non-invasive plant species. - Ecol. Lett. 13: 235-45.

van Kleunen, M. et al. 2015a. Global exchange and accumulation of non-native plants. - Nature 525: 100-103.

van Kleunen, M. et al. 2015b. Characteristics of successful alien plants. - Mol. Ecol. 24: 1954-1968.

van Kleunen, M. et al. 2018. The changing role of ornamental horticulture in alien plant invasions. - Biol. Rev. 93: 1421-1437.

van Kleunen, M. et al. 2019. The Global Naturalized Alien Flora (GloNAF) database. - Ecology 100: e02542.

van Kleunen, M. et al. 2020. Economic use of plants is key to their naturalization success. - Nat. Commun. 11: 3201.

van Wilgen, B. W. et al. 2020. Biological invasions in South Africa: an overview. - In: van Wilgen, B. W. et al. (eds), Biological invasions in South Africa. Springer International Publishing, pp. 3-31. 
Webb, C. O. et al. 2002. Phylogenies and community ecology. Annu. Rev. Ecol. Syst. 33: 475-505.

Weigelt, P. et al. 2020. GIFT - a global inventory of floras and traits for macroecology and biogeography. - J. Biogeogr. 47: 16-43.

Westoby, M. 1998. A leaf-height-seed (LHS) plant ecology strategy scheme. - Plant Soil 199: 213-227.

Westoby, M. et al. 1992. Comparative evolutionary ecology of seed size. - Trends Ecol. Evol. 7: 368-372.
Wirth, C. and Lichstein, J. W. 2009. The imprint of species turnover on old-growth forest carbon balances - insights from a traitbased model of forest dynamics. - In: Wirth, C. et al. (eds), Old-growth forests: function, fate and value. Springer, pp. 81-113.

Wright, I. J. et al. 2004. The worldwide leaf economics spectrum. - Nature 428: 821-827.

Zheng, W. 1983. Silva sinica. - China Forestry Publishing House. 